\title{
Real Time Monitoring in Disasters
}

\author{
Nigel Scott and Simon Batchelor
}

\begin{abstract}
This article discusses some of the opportunities emerging from the changing Information and Communication Technology (ICT) landscape for improving and enhancing agency response within the disaster cycle. There are constant calls for better coordination among agencies, of engaging with the community to improve resilience, of better governance, of community empowerment. Any action in a system affected by disaster will be guided by a complex mix of human response, socioeconomic context, political and power factors, and technology. The technology is only one component in a complex environment. Nevertheless, as this article outlines, recent shifts in the ICT landscape have not only created opportunities for more and timely data, they have opened the way for new ways of working. They have the potential to increase interagency cooperation, they have the potential to deliver community engagement, breaking free from extraction of information to a co-construction of data, and they even have the potential to empower citizens and to enable better governance.
\end{abstract}

\section{Introduction}

Organisations working on the ground immediately after a disaster always need to know what is needed, so any technology that provides information in real time will be immensely valuable. This article discusses some of the opportunities emerging from the changing Information and Communication Technology (ICT) landscape for improving and enhancing agency response within the disaster cycle. There are many ways in which technology can assist with the generation, interpretation and dissemination of information throughout the disaster cycle, and there is real potential for using ICT for enhancing the efficiency and effectiveness of disaster response.

\subsection{The disaster cycle framework}

In a good practice review, Twigg (2009) refers to the disaster cycle as a means of conceptualising different elements of disaster management. Even though he views this as 'an over-simplification, as the components do not fit together neatly or in exact sequence', and the concept has since been incorporated into current thinking on resilient communities and disaster risk reduction, it provides a simple framework for this discussion:

Mitigation: Any action taken to minimise the extent of a disaster or potential disaster.
- Preparedness: Specific measures taken before disasters strike, usually to forecast or warn against them, to take precautions when they threaten, and to arrange for an appropriate response (such as organising evacuation and stockpiling food supplies).

- Response: Actions taken immediately after a disaster to save lives and provide emergency assistance to affected communities.

- Recovery: Actions to restore communities to their pre-disaster conditions; this may well include mitigation measures designed to reduce the potential impact of future disasters (known as 'build back better').

Monitoring and evaluation is of value throughout the cycle for providing some form of accountability, and for generating an understanding of what works (and what does not). Monitoring tends to be associated with accountability - making sure that promises are delivered - whereas evaluation (without wanting to get too involved in the increasingly extensive theory and semantics of 'evaluation') provides a more qualitative judgement on how effective a project has been in achieving its desired objectives. It is the response phase of a disaster that presents particular challenges for field staff as they have to design programmes under extreme time constraints and based on limited information. It is, therefore, extremely 


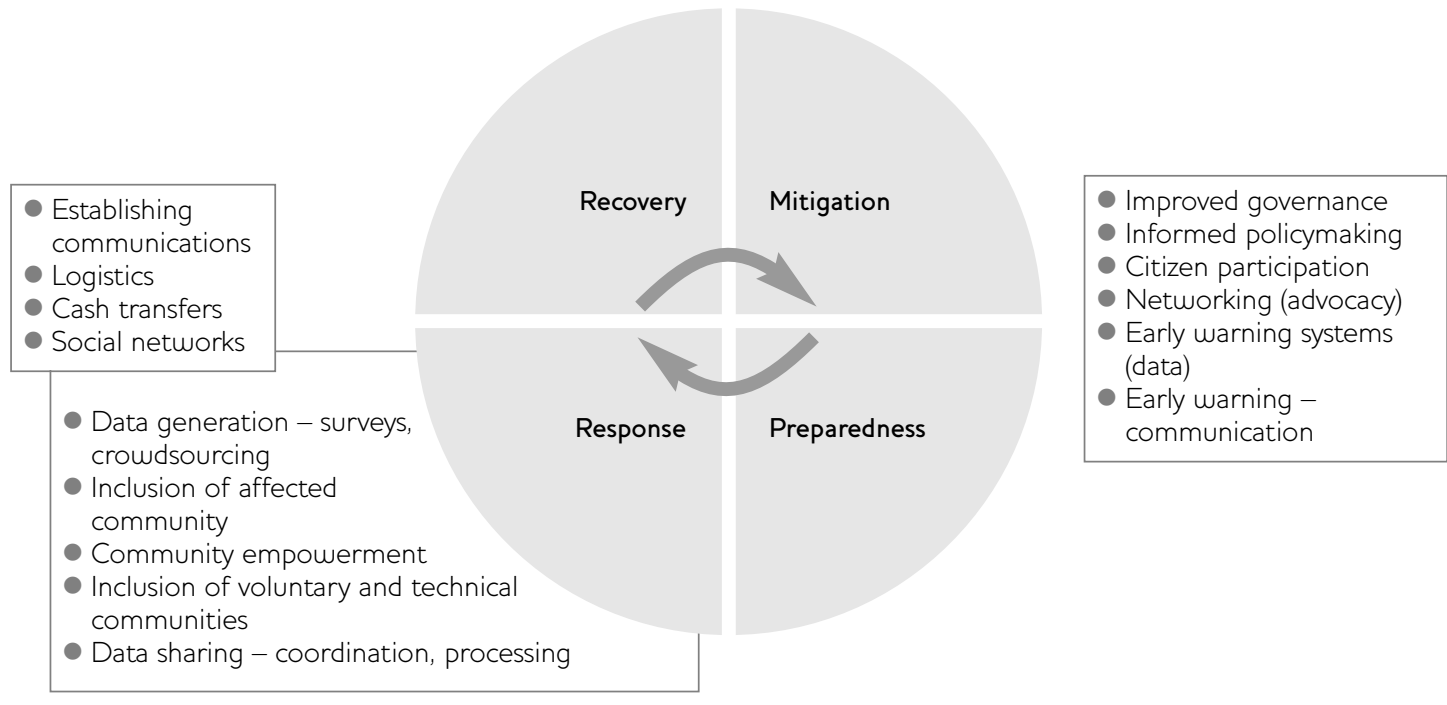

important to get feedback on how well a programme is performing as soon as possible (evaluation), and to make changes accordingly. This is where real-time monitoring offers huge potential. In recognition of this, the Inter-Agency Standing Committee (IASG) of the United Nations Office for the Coordination of Humanitarian Affairs (UNOCHA) set up a Real Time Evaluation Interest Group to explore the use of light and flexible evaluations as a joint evaluation methodology, which has since published a set of procedures and methodologies (OCHA 2011).

Other phases also have a requirement for information and feedback. 'Preparedness' for instance is a phase where recent changes in technology hold enormous potential for enhancing information flows. One such use is delivering highly sophisticated early warning systems based on space technology. However, preparedness also includes community resilience. The high-tech satellite approaches are far removed from the principles of community-based disaster risk management (CBDRM). CBDRM focuses on the ability of communities to take simple measures themselves to reduce their vulnerability. Recent changes in technology also provide new opportunities for this type of community engagement.

Finally, monitoring activities are typically carried out by agencies (e.g. government or nongovernmental organisations (NGOs)) and involve the extraction of information from beneficiaries. Although the value of more participatory approaches is recognised, agencies still struggle to balance this with time pressures on completing assessments. Communication technologies are beginning to upset this paradigm, as they enable affected communities to generate and access data themselves. Disseminating information to affected communities is important to help empower people to make informed decisions.

This article focuses on the response and preparedness phases and considers the emerging role of technology in generating data in real time (or at least getting closer to real time), in improving the quality of information and understanding derived from data, and in improving the extent to which information can be exploited and put to use through increased access; key issues considered are presented in Figure 1.

\section{Disaster response}

\subsection{The need for needs assessments}

This would appear to be the phase where access to real-time information would be of greatest benefit. The World Disasters Report 2005 (IFRG 2005) refers to examples of aid agencies not adhering to good practice, and providing inappropriate aid that does not meet the needs of the intended beneficiaries. This is a wellrecognised problem, and needs assessments are now advocated as best practice; for example, one of the principles of conduct for the International 
Red Cross and Red Crescent Movement and NGOs in disaster response programmes is that aid priorities are calculated on the basis of need alone:

Wherever possible, we will base the provision of relief aid upon a thorough assessment of the needs of the disaster victims and the local capacities already in place to meet those needs (IFRC 1995).

There are a multitude of approaches to conducting a needs assessment. A good deal of work has been done on looking for ways to coordinate approaches in order to improve consistency. For example, OCHA produced an interesting review of 15 needs assessment initiatives, categorised into pre-crisis, multicluster, and sector specific tools (OCHA 2009). Around the same time OCHA, through the IASC, was looking into Real Time Evaluations (RTEs) as a tool to be used consistently across organisations.

A real-time evaluation (RTE) is an evaluation in which the primary objective is to provide feedback in a participatory way in real time (i.e. during the evaluation fieldwork) to those executing and managing the humanitarian response (Cosgrave et al. 2009).

Although the distinguishing feature of RTEs is speed, Cosgrave et al. stress that they are not simply trying to do regular evaluations, only faster. They have to be more flexible, designed to be consistent with the capacity of staff and with conditions in the field. They have to be more modest in scope and methodological rigour. In the context of an RTE, 'real time' means within one or two weeks - a vast improvement on the timescales of more traditional evaluations, which can stretch to several months.

RTEs can be used iteratively to keep a finger 'on the pulse' of how a programme is performing or they can be used to generate understanding in response to a range of events:

- Programme design immediately after establishing a response programme;

- Changes in context, for example shifting populations, spread of disease;

- Problems becoming evident, for example vulnerable groups not receiving assistance;
Changes in programming, for example expanding into providing new services, making a decision to close down.

\subsection{The challenge of timely assessments}

In a review of three inter-agency RTEs conducted for OCHA, Telford (2009) highlighted inter alia problems with timing, costs and dissemination of information. He describes several reasons why timescales were stretched, including a preference for rigorous methods and delays in approving reports. Even though the cost of RTEs (in the order of 100,000 USD) represented a small fraction of total budgets, interviewees in the study regarded costs as high. Among other dissemination issues, reports were not even translated into local languages.

In addition to confirming a need for coordination in order to reduce duplication, OCHA (2009) emphasises the need to maximise the use of existing information in planning when timescales prevent the gathering of detailed information, and the need for standardisation both in terms of indicators used and terminology.

Garfield et al. (2011) also identified a number of challenges in carrying out needs assessments, which are generally associated with planning, organisational and personnel matters. A key concern is the design and timeliness of surveys. There are tensions between whether sampling should be purposive (survey affected or vulnerable communities only) or representative (capture all groups), whether sampling should be rigorous or not, and whether simply gathering observational information might be more useful than large-scale household surveys. They point out that it usually takes several weeks to get field survey teams mobilised, yet 'donors typically make their first funding decisions within ten days of a sudden-onset emergency, and make major allocations within six weeks'.

Lack of coordination of information gathering and sharing is also a key concern flagged by IFRC (2005). Duplication of assessments represents a waste of resources, but in the absence of strong overall coordination and driven by the expectations of donors, agencies can even end up effectively competing with each other. Nevertheless, agencies are generally aware of this, and the International Federation of Red Cross and Red Crescent Societies (IFRG) Code 
of Conduct includes specific recommendations on the sharing of information:

Planning and coordination can be greatly enhanced if NGHAs are provided with information on relief needs and government systems for planning and implementing relief efforts as well as information on potential security risks they may encounter (IFRC 1995).

In response to these issues, UNOCHA has convened a Needs Assessment Task Force (NATF) under the Inter-Agency Standing Committee (IASG). Although the task force has yet to complete its activities, it has published the review of assessment approaches referred to earlier (OCHA 2009) and a multi-cluster/sector initial rapid assessment manual, and is working on an internet dashboard to consolidate needs assessment and response information.

All of these reviews of assessment approaches also cite varying levels of capacity as an impediment to achieving consistency and to generating high-quality information. Not only may humanitarian agencies lack staff with the skills to design and conduct a needs assessment, but they may also lack the capacity to analyse and interpret the data.

\subsection{Opportunities for improving assessments}

\subsubsection{Data collection}

How then can technology help address these challenges? The emerging ICT has indeed led to considerable new opportunities for addressing these challenges, and as technology moves on into the future, is only likely to create even more innovative and imaginative ways of responding. Mobile phones, tablets and other mobile devices are making it easier than ever to gather reliable information from the field and process it quickly. Data collection is said to occur 20-30 per cent faster through the use of mobile devices (compared to paper and pencil methods), and statistical analysis of that data now takes hours rather than weeks. For example, the Vulnerability and Assessment Mapping Unit of the World Food Program (WFP) conducts both routine surveys to assess food security and data on food availability after disasters and conflicts. The Multi-cluster Rapid Assessment Mechanism (McRAM) project, which is supported by multiple agencies involved in emergency response, also used Personal Digital Assistant (PDA) technology in their first post- emergency assessments in Pakistan in March 2008. They use a variety of questionnaires which can be used with affected community groups either in their normal residential areas or in internally displaced person (IDP) camps. PDAs have now been superseded by mobile devices such as tablets for long-form surveys and large data sets (such as household interviews that can have thousands of questions).

Garfield et al. (2011) suggest the use of innovative technological solutions such as SurveyMonkey (web-based) or EpiSurveyor (running on mobile phones) for rapid data gathering. The IFRC provide an example of mobile phone-based data collection with their Management Survey Tool (MST), designed to gather public health information. ${ }^{1}$ Volunteers equipped with mobile phones loaded with the EpiSurveyor software conduct face-to-face interviews and input the data directly into the phones. Data is uploaded to a central server using GPRS networks, which are now commonly available across Africa. Programme staff can then interrogate and analyse the data using a web interface. The MST has been used in Kenya and Namibia, and in Nigeria it was used in a survey of 300 households to evaluate the impact of a campaign involving the distribution of half a million bed nets. Using the mobile phone system offered both cost and time savings over the traditional pencil and clipboard approach.

At this point we need to acknowledge the rapidly changing landscape of ICT. Throughout this article we are sharing recent examples of how technology has been integrated into activities within the disaster cycle. However, within 12 months of this article being published the technology may change significantly. For instance, EpiSurveyor is currently evolving, due to be re-released in 2013 as 'Magpi', and the use of GPRS networks may soon be overridden by higher bandwidth network technologies. Up-andcoming survey applications such as FormAgent and PoiMapper offer agencies new opportunities to create bespoke survey instruments for mobile devices without the need for specialist programming expertise. Our point is that any technological detail in this article may be out of date within 12 months; however, the principles behind the use of technology to overcome the challenges regularly found within the monitoring of the disaster cycle will remain. 


\subsubsection{Community inclusion}

Implicit in the literature on assessments is that they are conducted by institutions, who extract information from affected communities. Whilst this is the traditional survey approach, widespread use and ownership of mobile phones, even among vulnerable and isolated communities, means that alternatives are becoming available, as the development of mobile phone-based survey software shows.

In addition to making the extraction of data quicker and cheaper, widespread access to mobile phones means that affected people can also generate data for themselves. Crowdsourcing has attracted a good deal of interest recently, largely driven by the role that $\mathrm{Ushahidi}^{2}$ has played in a number of recent high-profile disasters. Crowdsourcing enables affected people themselves to generate data, and systems provide platforms that enable data to be collated from large numbers of participants.

Another characteristic of crowdsourcing is that it provides a mechanism for tapping the expertise of large numbers of people. Reuniting family members separated by disasters is a good example of a service that affected people themselves are best qualified for. It is common for registration details of displaced persons to be entered into databases that can then be interrogated, but Refugees United and their partners (United Nations High Commissioner for Refugees (UNHCR), Ericsson, and MTN) have developed a mobile phone-based app that enables displaced persons to take a more proactive role:

The programme enables refugees to use mobile phones to register themselves, search for loved ones, and subsequently reconnect via an anonymous database, using SMS or mobile internet. Refugees United maintains the information in the database, but the information registered can be used to search by refugees, NGOs and international organisations caring for displaced people, and use to put them quickly in touch with loved ones. Without the programme, locating displaced family members can often take years when based on traditional paper based systems (mew mobile app to reconnect refugess in Uganda). ${ }^{3}$

\subsubsection{Community empowerment}

One of the defining features of crowdsourcing is that it diminishes the distinction between amateurs and professionals. Traditionally, assessments would be carried out by highly qualified professionals with expertise in survey design and analysis, but crowdsourcing technologies enable anybody with a mobile phone to contribute data. The key to Ushahidi's success is that they adapted internet technology so that the system was compatible with relatively low-technology that was in the hands of Kenyan people.

A well-known example of Ushahidi's crowdsourcing platform was set up in Kenya. After the post-election violence erupted in Kenya, the government banned all live radio and television broadcasts and warned Kenyans about circulating news via Short Messaging Service (SMS). However, the Ushahidi platform provided a means of tracking the spread of violence by enabling citizens to post reports using SMS messages or email. The information then appeared on a Google 'mash-up' (a web page combining diverse forms of information from diverse sources) on the website ${ }^{4}$ where it could be verified and utilised by NGOs.

\subsubsection{Data sharing}

There remain opportunities for multiple organisations to gather data (including geospatial and data tagging) using standard indicators, which can be made openly available and interrogated by a range of interested parties. Standards are the key to this, as well as sorting practical issues associated with infrastructure (e.g. who will run web servers). This would appear to be an obvious extension of collaborative work already done by the NATF. However, the examples above illustrate how the benefits of making data available for sharing can go way beyond simply enhancing coordination between humanitarian agencies. A discussion of how communications technology impacted on the response to the January 2010 earthquake in Haiti gives a much richer picture of what can be achieved:

For the first time, members of the community affected by the disaster issued pleas for help using social media and widely available mobile technologies. Around the world, thousands of ordinary citizens mobilized to aggregate, translate, and plot these pleas on maps and to 
organize technical efforts to support the disaster response. In one case, hundreds of geospatial information systems experts used fresh satellite imagery to rebuild missing maps of Haiti and plot a picture of the changed reality on the ground. This work done through OpenStreetMap - became an essential element of the response, providing much of the street-level mapping data that was used for logistics and camp management (Harvard Humanitarian Initiative 2011).

Whereas participatory approaches involving affected communities are well established in good practice, this document highlights the role that can be played by volunteer and technical communities (V\&TGs) - a disparate group of anonymous individuals from across the globe. This group is new to the field, and the document proposes ways in which V\&TCs can be included in humanitarian responses.

\section{Response management}

\subsection{Establishing communications}

In order for technology to contribute to overcoming disaster response challenges, communication networks need to be operational. Several initiatives exist to establish some form of communications network as a priority immediately after a disaster, which tends to damage existing telecommunications infrastructure.

Télécoms Sans Frontières (TSF) is an NGO dedicated to getting communication facilities set up and running as quickly as possible. This initial response phase is the most time critical part of any emergency - when lives can be saved. TSF crews of IT and telecoms specialists claim that they can intervene anywhere in the world in less than 24 hours to provide emergency telecom services. Services they provide in the field are: ${ }^{5}$

- Initiate a humanitarian-calling operation;

- Establish multiple emergency telecommunications centres for first responders; and

- Conduct ICT assessments to assist with recovery planning if required.

Besides its response to major emergencies, TSF also uses its experience as the first NGO specialising in emergency telecommunications to build the capacity of other relief organisations and of national disaster response agencies in telecommunications and information technologies. UNICEF has a standby arrangement with TSF, enabling a reduced deployment time.

The UN-Ericsson partnership, which is facilitated by the United Nations Fund for International Partnerships (UNFIP), involves UN agencies that address emergency response and mitigation as well as the IFRC. The Ericsson Response (ER) programme falls under the company's corporate responsibility programme, and provides employees with an opportunity to contribute to emergencies. The programme aims to support relief organisations by providing a communication network, which they claim can be set up within five hours. ${ }^{6}$ It is perhaps worth noting that the use of telecommunication infrastructure in emergency response has been discussed by telecommunications regulators throughout Africa. Mongi (2007) reports that the main recommendations stemming from the Forum are as follows:

- ICTs should be included in all phases of disaster management and planning.

- The Hyogo Framework for Action 2005-2015 (HFA) should be implemented fully (see Section 4.1).

- Disaster risk reduction facilitates the implementation of sustainable development.

- Public Protection and Disaster Reduction are integral parts of disaster management; they should be treated as one part, not two separate groups.

- Satellites have a higher capacity to implement effective disaster relief and response systems; they should be included as part of the disaster management policy formulation process.

- Youth have an important role to play in disaster management.

- Regulators and operators must work together in carrying out disaster management plans.

\subsection{Logistics}

Response activities will almost certainly involve the distribution of materials to vulnerable groups, and subsequent monitoring of the distribution of items is an important part of ensuring that the programme is working effectively, and an important part of accountability. Tracking inventory data, stock levels, and location data are all fundamental, and well suited to collection and transmission through communications technology. Key 
features of solutions are that multiple field devices can be used to gather data (e.g. numbers of items distributed), communications networks are used to transmit data to central computer networks, and web interfaces can be used to interrogate and interpret data making good use of visualisation software.

\section{The ICT Humanitarian Emergency Platform} (HEP) is a collaborative website hosted by the UN WFP that is intended to support the ICT community working in emergencies. The Emergency Preparedness Integration Centre (EPIC) is one of two projects supported by the HEP. It serves as an example of how an integrated package of technologies can enhance coordination and management. A proof of concept deployment of EPIC in the occupied Palestinian Territories in 2010 was used to send and receive food shipment information in real time, streamlining commodity handover and tracking in the field:

Replacement of the current paper-based system with an automated one allows waybill information to be accessed through an online portal by both distributing and receiving warehouses. Staff at both can log in to the system at any time and have immediate access to all information concerning the shipment, for example what was sent, when it was sent, when it will arrive and the shipment's condition. Real-time access to such details ensures more accurate and efficient movement of goods, increased data integrity and elimination of critical lags in the data transfer cycle (EPIC proof of concept).

\subsection{Cash transfers}

It should also be noted that the rapid growth in the use of mPayment systems in social protection schemes targeting poor and vulnerable individuals and households (Vincent and Cull 2011 ) is also generating very large quantities of real-time information tracking transfer payments to these groups. IFRC point to a number of advantages over more traditional mechanisms for distribution of assistance, even in the response phase following a disaster:

Cash transfer programming can be used to address basic needs for food and income and/or to protect, establish or re-establish livelihoods or productive capacity.
- Cash transfers allow recipients to obtain a range of goods and services of their choice directly from local markets and service providers.

- Cash can often be delivered more quickly than in-kind commodities.

- The provision of cash alone is not always sufficient - link cash transfer programmes to other forms of support.

- Monitoring and evaluation of cash transfer programmes have shown that risks of abuse are no greater than for other forms of commodity response; procedures to prevent abuse are necessary for all programmes (ICRC 2007).

Interestingly, the International Committee of the Red Cross (ICRC) guidelines written in 2007 make no mention of mobile money systems as a means of making indirect transfers to beneficiaries, but by 2011 mobile phone transfers were specifically recognised in a study on disaster preparedness in the Philippines (Poisson 2011). Bear in mind that the Philippines has a long history of mobile payments systems, as GCASH was one of the first mobile money systems in the world. In addition to mobile money, the Philippines study describes a number of other technology-based solutions, such as remittance transfers (recipients visit the branch of remittance company to collect cash), prepaid cards and ATMs. Electronic mechanisms overcome some of the key drawbacks of cash transfer programmes, notably corruption and wastage (payments can be made directly to beneficiaries), targeting specific beneficiaries, and accountability. The continuing development of cashless systems in low-income countries is likely to enhance the use of cash transfers:

Of 40 transfer programmes launched in the past decade (for which detailed data is available), almost half (45 per cent) feature electronic delivery of cash payments (Arnold $e t$ al. 2011).

\subsection{Social networks}

Sites such as Facebook, YouTube and Twitter can be used by citizens to communicate (and keep track of one another) within communities affected by emergencies, and within a diaspora. This can provide an effective means of sourcing support and assistance. However, peer-to-peer communications facilitated by social networking sites can also be used for one-to-many 
communication, and this has proven particularly valuable in raising awareness of conflict both nationally and internationally. A powerful example was the posting of video clips of riots in Iran on the internet, which were picked up and broadcast around the world by television stations unable to post their own reporters in the country. This example was picked up by Coyle and Meier (2009) in the introduction to their review of information and social network in emergencies:

On 13 June 2009, thousands of Iranians poured into the streets to protest what they believed to be a flawed national election. With the Iranian regime restricting internet access and banning journalists' access to key demonstrations, communications via text messaging and social networks became a crucial tool for information sharing between the protesters and the outside world, and even a source for the news media. So critical was this source of information that the U.S. State Department asked Twitter to delay a scheduled network upgrade that would have shut down the site for some hours on June 15 and 16.

However, they immediately draw attention to some of the challenges associated with networking technology:

Yet both hoaxers and Iranian officials also are said to have used these same communications networks to post false information. Without a trusted process of vetting, misinformation gained currency simply by being constantly repeated or re-Tweeted. One such instance was the claim that the election monitoring committee had declared the result invalid.

Another was the initial circulation of a photograph said to be of a young woman killed in one of the Tehran demonstrations; the wellknown picture was of another woman with the same first name.

It is important to remember that simple voice calls and SMS messages are also an important part of enabling people to access their social networks. This is reflected in the urgency placed on getting communications networks up and running as soon as possible after a disaster event.

\section{Mitigation and preparedness}

While the above has focused on the response phase, there are a number of emerging opportunities for other parts of the disaster cycle.

\subsection{Advocacy}

The growth of the communications industry over the last decade, and the adoption of communications technology by low-income countries in particular, mean that communications networks have now percolated down to communities almost all over the world. Even small, local NGOs are typically equipped with a laptop and an email account, even if this needs to be accessed at a cybercafé. This provides emerging opportunities for networking and sharing with a multitude of grass roots organisations.

One such example is the Global Network for Disaster Reduction (GNDR), a network of civil society organisations working to improve disaster risk reduction policy and practice at every decision-making level. Views from the Frontline (VFL) is a multi-stakeholder engagement process that monitors aspects of local governance required to build disaster-resilient communities, and provides a basis for dialogue between stakeholders. The Hyogo Framework for Action 2005-2015 promotes a strategic approach to reducing vulnerabilities and risks to hazards, with the ultimate goal of reducing disaster losses by 2015. The United Nations Global Assessment Report on Disaster Risk Reduction presents an analysis of disaster risks including an overview of progress towards the Hyogo Framework for Action based on self-assessment of progress by over 130 governments. VFL aims to fill a gap in the monitoring process by providing a complementary view of progress based on the experience and views of people living in disasterprone communities - those at the 'frontline'. Local organisations gather both qualitative case studies and quantitative data from face-to-face surveys. In 2011 VFL also trialled an experimental programme to research the use of SMS surveys using mobile phones.

Over 20,000 face-to-face and 36,000 mobile phone interviews were conducted by over 500 organisations in 69 countries (GNDR 2011). The short survey comprised 29 questions mostly covering views on local government issues relating to inclusion and participation, policies and capacity, and accountability and transparency. The main benefit to an organisation like GNDR of using mobile phone surveys is cost. Partner organisations have estimated that the overall cost of face-to-face interviews was around $\$ 125$, which includes 
training, mobilising communities, transport and logistics - the total cost of the mobile phone interviews worked out at just under $\$ 5$.

\subsection{Early warning systems}

The impact of disasters can be greatly reduced if people are aware of an impending disaster and know what action to take in the event of a disaster. Achieving preparedness is, therefore, dependent on establishing effective channels of communication between institutions that monitor threats, such as meteorological offices, and vulnerable communities. It is no surprise, then, that telecommunications technologies are a fundamental part of many early warning systems that can be found across the world. The first part of this section describes a number of programmes that use technology to gather data for the purposes of monitoring potential hazards, and the second part describes examples of programmes that use technology to disseminate warnings among at risk communities.

\subsubsection{Monitoring - gathering data}

This section gives three examples of ways in which technology can be used to gather data that can then be used to track the onset of hazardous conditions. These examples are interesting because they deal with quite different types of data, yet they all illustrate the power of being able to track changes over time. These may be regarded as examples of 'real-time' monitoring, even though they work on quite different timescales.

Satellite imagery provides the ability to take a snapshot of conditions on the ground across large areas of land. A time series of images can be used to track the onset of disasters such as crop failure, drought and disease. Coyle and Meier (2009) point out that this type of technology is especially valuable in remote or politically inaccessible locations. One example of the use of satellite technology is the Disaster Management System (DMS) run by the Indian Space Research Organisation (ISRO).

The DMS provides timely support and services from aerospace systems, both imaging and communications, to support efficient management of emergencies. The DMS programme addresses disasters such as flood, cyclone, drought, forest fire, landslide and earthquake. The services provided include creation of digital databases for facilitating the identification of hazard zones and damage assessment; monitoring the progress of major natural disasters using satellite and aerial data; development of appropriate techniques and tools for decision support; establishing a reliable satellite-based communications network; deployment of emergency communication equipment; and R\&D towards early warning of disasters. ${ }^{8}$

DMS is creating core and hazard-specific geospatial databases for the entire country, and is gathering information to identify flood hazard zones and model tsunami storm surges. A range of technologies are used including geostationary satellites (communication and meteorological), low earth orbiting and earth observation satellites, aerial survey systems (e.g. laser terrain mapping, radar, digital camera), and groundbased observation systems. In the event of a disaster, real-time information from airborne and spaceborne sources can be acquired, processed and analysed. Utilising this data in conjunction with geographic information system (GIS) databases comprising thematic maps and socioeconomic information, the DMS Decision Support Centre is able to provide decision support to relevant agencies.

Similar in some respects to the DMS example is the Global Information and Early Warning System on Food and Agriculture (GIEWS) hosted by the Food and Agriculture Organization (FAO). The system monitors a range of sources of information on food supplies and demand across the globe in order to inform policymakers, and to warn of impending food crises. The interesting feature of the GIEWS system is that it draws upon data from a large range of sources.

GIEWS is an open forum for the exchange of information on food security. The system continually receives economic, political and agricultural information from a wide variety of official and unofficial sources. Since 1975, institutional links and information-sharing agreements have been established with several UN organizations, 115 governments, 4 regional organizations and 61 NGOs.

Numerous international research institutes, news services, private sector organizations, and specialized government agencies also collaborate (GIEWS brochure). ${ }^{9}$ 
Anthropometric measurements are most commonly used as indicators of nutritional status, and ICTs lend themselves to the routine collection and analysis of large amounts of such data. An example of more micro-level data gathering is provided by UNICEF's RapidSMS Open Source software, which has been used to create a mobile phone-based system for data collection for nutrition and food security surveillance in Malawi. However, these types of measurements are late-stage indicators, using malnutrition indicators to identify conditions of food insecurity that have already manifested.

\subsubsection{Early warning communications}

The Disaster and Emergency Warning Network (DEWN) is a multi-modal communication system built on a suite of Global System for Mobile (GSM) technologies that is designed for the crucial task of alerting agencies and individuals when a disaster occurs, and serves as an example of how multiple channels of communication need to be used to disseminate time-critical information. The system was designed and funded by Dialog Axiata, Sri Lanka's largest telecommunications provider, and was used as a case study in UNICEF's Mobiles for Development project (Boakye et al. 2010).

When institutions such as the Pacific Disaster Centre and the Sri Lanka Meteorology Department send information on a potential disaster to the Disaster Management Centre (DMC), it is first verified, and then customized alerts are issued.

SMS is used for directed messages while Cell Broadcasting is used for mass-alerts. Cell Broadcasting is well suited to disaster operations since it is immune to network congestion (it makes use of an 88 byte message sent by base stations to all handsets in a cell area). Messages can be sent selectively, based on geographical area, to specific individuals or groups of recipients (e.g. members of the emergency services, key community contacts), or to the general public, as directed by the authority generating the message. The system is compliant with the Common Alerting Protocol (CAP), an internationally recognised standard that enables the authorized entity to distribute the same warning message to multiple media (radio and TV broadcast stations, cellular networks, satellite radio systems, fixed telephone networks etc.) in one operation.

Although warning messages can be displayed on any GSM handset, smartphone owners can also download free software that causes the phone to ring continuously until acknowledged, and displays the alert message in any of three local languages. In addition to mobile phone handsets, messages can be received by a special-purpose wireless alarm device currently built on a $2.5 \mathrm{G}$ module, which is designed to be fixed indoors in public buildings such as places of worship, hospitals, markets, etc. It contains a loud siren, a flashing lamp, an LCD display, a radio, and inbuilt call-back facility (Boakye et al. 2010).

Although there are other examples of the use of commonly accessible technologies (notably mobile phones) to warn citizens of rapid onset disasters, most systems still rely on traditional broadcast media to disseminate warnings. The technology lends itself to improving the accuracy and timeliness of early warning information, but in order to effectively reduce disaster losses it is also essential that this information is acted upon in an appropriate and timely manner:

Early warning is not only the production of technically accurate warnings but also a system that requires an understanding of risk and a link between producers and consumers of warning information (IFRC 2005).

This highlights the importance of the role played by local disaster risk reduction organisations, such as those in the GNDR, and the participatory approaches often employed by these types of organisations.

\section{Opportunities arising}

We have seen above that there are emerging opportunities for increasing the timeliness and quality of information flows in the disaster cycle. In this section we explore the opportunities and challenges the sector faces in the coming years.

\subsection{Data}

Existing initiatives are moving ever closer to the goal of making standard data available for sharing among humanitarian agencies. Opportunities to close gaps remain in many areas such as: 
- Standards for the collection of data (e.g. survey indicators);

- Data standards for databases;

- Rights/legal issues;

- Infrastructure.

Opening up access to data will help improve coordination, break down the competitive practices, and make processes more transparent. Crucially, it will open up new possibilities for affected communities (including the diaspora) to respond to changing circumstances. Within the development community more broadly there is already a good deal of inertia regarding open data, such as the Global Pulse initiative (see Section 5.3).

\subsection{Participation}

When conducting an assessment there is always a tension between rapid and participatory approaches. Time pressures require rapid assessments, but mobile technology means that it is becoming possible to gather data from large numbers of affected people in short timescales. Crowdsourcing provides a mechanism for people to generate data themselves. Moreover, best practice suggests that there is often value in involving affected people themselves in the interpretation of data. Sharing data with affected communities (through crowdsourcing platforms) provides opportunities for affected people to apply indigenous knowledge to the processing and interpretation of data.

Peer-to-peer communication through voice and SMS, as well as internet-based social networking platforms such as Facebook and Twitter, are of value in sourcing support and accessing the information needed to make decisions.

Networking technology facilitates the participation of local organisations that work in disaster risk reduction in national-level planning and preparedness processes. GNDR is an example of a global network that engages with international-level processes.

\section{IFRC recognises the value of 'beneficiary} communications' as a two-way communication process making use of a mix of communication media and technologies, from face-to-face meetings to SMS messaging and crowdsourcing.

Community engagement is nothing new but there is an exciting new dimension that brings new momentum and opportunities. But it's not about technology alone. It's about how we use them, and our huge network of volunteers, to really put power into the hands of the people whose destinies we are able to influence

(IFRC website). ${ }^{10}$

\subsection{Big data}

This article has discussed the collection, interpretation, and dissemination of information specifically related to the monitoring of activities throughout the disaster cycle. Implicit in all of this is the assumption that monitoring activities generate information that will hold the answers to, or at least some understanding of, specific questions arising from the management of humanitarian activities. There is no reason to challenge this assumption, but the emerging discipline of 'big data' challenges the idea that this is the only way of gaining insight into these questions. In addition to dealing with very large amounts of data, one of the interesting features of big data is the ability to derive understanding from apparently unrelated data. This is referred to as 'data exhaust' - digital data left by people as they go about their daily lives.

There are some fascinating examples of inferences that can be made by mining this type of data, and Global Pulse is a UN initiative looking at possibilities of tracking and predicting using mobile phone data (e.g. expenditure, duration of calls, routing of calls). In his paper on big data for development, Letouze (2012) gives some mostly health-related examples of the kinds of trends that can be modelled:

- Google Flu Trends used data on queries for flu-like symptoms to show that it is possible to identify outbreaks of disease in advance of more formal mechanisms. Similar work has been done with Google Dengue Trends.

- Health-related tweets were used to model flurate patterns in the USA.

- Activities on Facebook pages were used to identify drinking problems among college students in the USA.

He offers suggestions of ways in which big data can contribute to global development:

1) Early warning: early detection of anomalies in how populations use digital devices and 
services can enable faster response in times of crisis;

2) Real-time awareness: Big Data can paint a fine-grained and current representation of reality which can inform the design and targeting of programs and policies;

3) Real-time feedback: the ability to monitor a population in real time makes it possible to understand where policies and programs are failing and make the necessary adjustments (Letouze 2012).

Letouze points out that using big data for development is not easy, and discusses a number of challenges. Nevertheless, as more and more people affected by disasters have access to digital technology (typically mobile phones), the amount of data exhaust they generate will increase, so there is every reason to believe that in time this approach will provide a rich source of real-time information that will be of value in managing disaster responses and preparedness.

\section{Conclusion}

This rapid overview of some of the opportunities of technology has been built on the standards of

\section{Notes}

1 www.ifrc.org/en/news-and-media/newsstories/africa/nigeria/using-cell-phones-tocombat-malaria-in-nigeria/ (accessed 15 January 2013).

2 A free and Open Source platform that enables crowdsourcing for social activism using multiple channels including SMS, email, Twitter and the web.

3 http://reliefweb.int/sites/reliefweb.int/files/ resources/5A978018F439F98985257798007150 30-Full_Report.pdf (accessed 15 January 2013).

4 Graphics available at: http://kenya.ushahidi.com/ main (accessed 15 January 2013).

\section{References}

Arnold, C.; Conway, T. and Greenslade, M. (2011) DFID Cash Transfers Literature Review, Policy Division, London: Department for International Development

Boakye, K.; Scott, N. and Smyth, C. (2010) Case Studies: Mobiles for Development, New York: UNICEF

Cosgrave, J.; Ramalingam, B. and Beck, T. (2009) Real-time Evaluations of Humanitarian Actions: An ALNAP Guide Pilot Version, London: Overseas Development Institute good practice within the disaster cycle. It shows how Information and Communication

Technology is narrowing the gap between ideal concept of real-time monitoring and what can be achieved in practice, even though new technology brings new challenges. Needs assessments can take advantage of mobile technologies to generate detailed and timely data, and networking technologies open up new sources of data and new resources for processing data. Networking makes data sharing in real time possible, with positive implications for coordination, participation, and community empowerment. Networking enables affected communities to draw upon their own social networks, and to communicate locally, nationally and internationally. Networking also brings opportunities for affected communities to contribute to mitigation and preparedness planning and monitoring, as well as effective early warning systems. Recent shifts in the ICT landscape have not only created opportunities for the exchange of information, they have perhaps opened the way for new ways of working.

5 www.tsfi.org/en/presentation/action/48organisation-humanitaire-durgence (accessed 15 January 2013).

6 www.ericsson.com/thecompany/ sustainability_corporateresponsibility/ ericsson_response (accessed 15 January 2013).

7 http://ictemergency.wfp.org/web/ictepr/epicproof (accessed 15 January 2013).

8 www.isro.org/scripts/disastermanagement system.aspx (accessed 15 January 2013).

9 www.fao.org/giews/english/about.htm (accessed 15 January 2013).

10 www.ifrc.org/en/what-we-do/beneficiarycommunications/ (accessed 15 January 2013).

Coyle, D. and Meier, P. (2009) New Technologies in Emergencies and Conflicts: The Role of Information and Social Networks, Washington DC and London UK: UN Foundation-Vodafone Foundation Partnership

Garfield, R.; Blake, C.; Chatainger, P. and Walton-Ellery, S. (2011) Common Needs Assessments and Humanitarian Action, London: Overseas Development Institute GNDR (2011) If We Do Not Join Hands: Views from the Frontline, Global Network for Disaster Reduction 
Harvard Humanitarian Initiative (2011) Disaster Relief 2.0: The Future of Information Sharing in Humanitarian Emergencies, Washington DC and Berkshire UK: UN Foundation and Vodafone Foundation Technology Partnership ICRC (2007) Guidelines for Cash Transfer Programming, Geneva: IFRC and ICRC

IFRG (2005) World Disasters Report 2005. Data or Dialogue? The Role of Information in Disasters, Geneva

IFRC (1995) The Code of Conduct for the International Red Cross and Red Crescent Movement and Non-Governmental Organisations (NGOs) in Disaster Relief, Geneva

Letouze, E. (2012) Big Data for Development?: Challenges and Opportunities, New York: Global Pulse

Mongi (2007) Using ICT for Effective Disaster Management, African Forum Event Report, Commonwealth Telecommunications Organization, hosted by Tanzanian Ministry of Infrastructure Development and the Tanzania Telecommunications Regulatory Authority OCHA (2011) Inter-Agency Real Time Evaluation (IA RTE) of Emergency Humanitarian Operations,
Developed by the IA RTE Steering Group, http://ochanet.unocha.org/p/Documents/ Revised_IA_RTE_Procedures_and $\% 20$ Methodologies\%202011_10_06.pdf (accessed 18 January 2013)

OCHA (2009) Assessment and Classification of Emergencies (ACE) Project. Mapping of Key Emergency Needs Assessment and Analysis Initiatives, United Nations Office for the Coordination of Humanitarian Affairs

Poisson, G. (2011) Cash Transfer Programming in Emergencies. Cash Transfer Mechanisms and Disaster Preparedness in the Philippines, Oxford: Cash Learning Partnership (CaLP)

Telford, J. (2009) Review of Joint Evaluations and the Future of Inter-Agency Evaluations

Twigg, J. (2009) Disaster Risk Reduction. Mitigation and Preparedness in Development and Emergency Programming, London: Humanitarian Policy Group, Overseas Development Institute

Vincent, K. and Cull, T. (2011) 'Cell Phones, Electronic Delivery Systems and Social Cash Transfers: Recent Evidence and Experiences from Africa', International Social Security Review 64.1: 37-51 